\title{
PROCESSING OF TECHNOGENIC LEAD-CONTAINING INTERMEDIATES USING COMPLEXING AGENT SOLUTIONS
}

\author{
V. A. Sergeev, Yu. F. Sergeeva,
}

UDC 669.4

S. V. Mamyachenkov, O. S. Anisimova, and S. V. Karelov

Methods are reviewed for processing technogenic lead-containing waste from nonferrous metallurgy enterprises. Use of different amine and phosphorus-containing complexing agents is considered. Process characteristics are provided.

Keywords: lead, cake, dust, complexing agent, leaching, carbonization, deposition, electro-extraction.

In Ural enterprises, copper and zinc are obtained from sulfide polymetallic concentrates containing: 12-20\% $\mathrm{Cu}$, $0.5-7 \% \mathrm{Zn}, 25-35 \% \mathrm{Fe}, 0.1-5 \% \mathrm{~Pb}$, and $25-40 \% \mathrm{~S}$. Ural metallurgical enterprises produce copper metal by various pyrometallurgical methods, but mainly each of them is preparation of a matte and its subsequent conversion. Zinc production by a classical pyrometallurgical scheme commences with firing zinc concentrate in a fluidized bed furnace.

Pyrometallurgical processes are accompanied by accumulation of metallurgical coarse and fine dust. Coarse dust is the result of mechanical carry-over of charge particles. Its composition differs little from charged material, and therefore it is returned to the process together with the original charge. Fine dust forms as a result of sublimation of compounds having a high dissociation vapor pressure. This relates to compounds of zinc, lead, cadmium, and rare metals. With a high zinc oxide content in fine dust, it is treated with sulfuric acid, as a result of which a cake is formed rich in zinc. It is necessary to process these products by separate technology.

At the contemporary level of technology, development secondary raw material treatment uses pyrometallurgical processes such as melting in shaft, rotary, Ausmelt reverbatory furnaces, in electric furnaces, in a Vanyukov furnace, melting in a flame reactor, etc. Pyrometallurgical methods have high productivity, although they have serious disadvantages:

1) it is necessary to use starting materials with a relatively high (not less than $30 \%$ ) main metal content:

2) the multistage nature of technology, i.e., relatively low level of direct metal extraction into finished product. Lead is partly converted into industrial product whose processing is carried out by special production schemes. Expenditure on finishing extraction is high, and in turn may lead to making production more expensive; and

3) the ecological risk of production.

An alternative to the high-temperature pyrometallurgical processing method for secondary raw material is hydrometallurgical technology schemes. The overwhelming majority of them use sulfuric, hydrochloric, and nitric acids. Leaching is also performed in alkaline or acidified salt solutions.

Use of chlorides leads to release of chlorine gas, i.e., an extremely corrosive and highly toxic substance, especially in a moist atmosphere and at elevated temperature. Sulfates have not been used extensively connected with the low solubility of lead sulphate in water. With use of alkaline solvents, there is a difficulty in regenerating solvents and their utilization.

Yeltsin Ural Federal University (UrFU), Yekaterinburg, Russia; e-mail: vertex2003@mail.ru. Translated from Metallurg, No. 1, pp. 83-85, January, 2013. Original article submitted March 5, 2012. 
In contrast to acid and salt solutions, alkylamines are not corrosive with respect to various grades of structural steels $[1,2]$. Use of complexing reagents provides selective lead extraction from lead-containing intermediates. During hydrometallurgical processing of lead-containing technogenic intermediates the solvent should have sufficient selectivity and provide the possibility of regeneration.

An amine used for processing lead-containing technogenic accumulations is ethylenediamine (EDA) [3]. Aqueous solution are used with EDA concentration of $200-240 \mathrm{~g} / \mathrm{dm}^{3}$. Lead-containing material, washed from copper sulphate and sulfuric acid to $\mathrm{pH}$ not below 3 in washing water, is leached within a closed reactor with a stirrer rotation rate of not less than $300 \mathrm{rpm}$. During leaching, the optimum EDA concentration is maintained, for which the reactor is fitted with a special dispenser for feeding concentrated reagent, and the $\mathrm{L}: \mathrm{S}$ is maintained at a level of 2:1. After leaching the pulp is filtered, the high grade lead-containing solution (in $\mathrm{g} / \mathrm{dm}^{3}: \mathrm{Pb} 90-180, \mathrm{Cu} 1-4, \mathrm{Ni} 0.1-0.5$ ) enters for cleaning from admixtures, and the slurry is sent for extraction of other valuable components.

Cleaning solution from admixtures is performed by cementation in a rotary cementation unit. The cementing material used is lead metal in the form of turnings, granules, or powder. The process lasts $90 \mathrm{~min}$, intensified by heating the solution to $35-50^{\circ} \mathrm{C}$ After cementation the pulp is filtered, the residue is melted, and the filtrate is subjected to carbonization.

Carbonization is performed with carbon dioxide within a sealed reactor with intense mixing. Accumulation of the basic lead carbonate is accompanied by release of heat, and excess of which leads to breakdown of the complexing agent, and therefore the reactor is fitted with a cooling unit. Carbon dioxide consumption is equivalent to double the lead content in solution. The basic carbonate obtained is washed with hot water at $60-70^{\circ} \mathrm{C}$. The washed basic lead carbonate is dried at $400^{\circ} \mathrm{C}$ for $4 \mathrm{~h}$, ground, and calcined at $450-480^{\circ} \mathrm{C}$ for $15-20 \mathrm{~h}$ with preparation of finished red lead. Solution after lead carbonate deposition is regenerated by adding lime and sent to the head of the process for leaching.

An effective and ecologically consistent reagent is an aqueous solution ethylenediaminetetraacetic acid (trilon-B) [4]. The technology proposed consists of three main units: leaching, cleaning the solution obtained, and electro-extraction of lead with return of solvent to the head of the process.

Studies have been carried out [5] on leaching lead-containing technogenic wastes with determination of optimum parameters for performing the process: trilon $\mathrm{B}$ starting concentration $100 \mathrm{~g} / \mathrm{dm}^{3}, \mathrm{pH}=7, \mathrm{~L}: \mathrm{S}$ ratio $=7-8$, temperature $20-25^{\circ} \mathrm{C}$. Under these conditions, lead extraction from solution is close to $96 \%$, zinc $30 \%$, copper $20 \%$, and iron remains in small amounts in a cake.

Treatment of the trilon-treated solution from metal admixtures (mainly zinc and copper) is based on the different solubility of EDTA salts with a change in medium acidity. With a reduction in $\mathrm{pH}$ to $1.0-1.5$, there is a breakdown in trilontreated complexes with accumulation of an EDTA deposit. It is desirable to acidify solution with sulfuric acid for coprecipitation together with EDTA of lead in sulfate form, and zinc and copper remain in solution in the form of sulfates. The residue obtained is filtered and washed with acidified water (in order to avoid dissolution and loss of EDTA in washing water) in order to remove metal admixtures and treated with alkaline solution calculated for preparing electrolyte with lead concentration of $40 \mathrm{~g} / \mathrm{dm}^{3}$ and $\mathrm{pH}=10$ [6].

Electrolytic extraction of lead was carried out in a two-chamber closed electrolyzer with partitions made of cationexchange membrane grade MK-40. The catholyte solution was lead trilonate, and the anolyte was weakly-acid sulfate solution. The membrane was intended for preventing EDTA anions entering the anodic chamber and their oxidation as a result of electrochemical reactions. Spongy lead was obtained, which after washing with water and melting under a covering layer of flux, corresponds to grade S1 according to GOST 1467-93. The current efficiency is $93 \%$, and electric power consumption is $3100 \mathrm{~kW} \cdot \mathrm{h} / \mathrm{ton}$ of lead. The treated catholyte contains: $2.3 \mathrm{~g} / \mathrm{dm}^{3} \mathrm{~Pb}, 68.9 \mathrm{mg} / \mathrm{dm}^{3} \mathrm{Zn}, 0.27 \mathrm{mg} / \mathrm{dm}^{3} \mathrm{Cu}, 11.8 \mathrm{mg} / \mathrm{dm}^{3} \mathrm{Fe}$, and after $\mathrm{pH}$ adjustment the complexing agent concentrated solution may be used at the head of the process for leaching starting lead intermediates.

A disadvantage of ethylenediaminetetraacetic acid is its low solubility in water at room temperature, i.e., not more than $120 \mathrm{~g} / \mathrm{dm}^{3}$, which makes it impossible to obtain lead solution with a high metal concentration. Lead trilonate also has limited solubility in water and it does not exceed $50 \mathrm{~g} / \mathrm{dm}^{3}$. These disadvantages make it difficult to obtain a compact cathodic deposit. 
Apart from amine compounds for treating technogenic lead-containing waste it is possible to use organophosphorus compounds. A widely known representative of this class of complexing agent is hydroxyethylene disphosphonic acid (HEDP), used as an inhibitor for boiler scale accumulation in heating units.

In the faculty of ferrous and nonferrous metallurgy of the Ural Federal University, new technology has been developed for processing technogenic accumulations in metallurgical enterprises using aqueous solutions of HEDP. In contrast to

trilon B, HEDP has significantly greater solubility in water at room temperature, which exceeds $1000 \mathrm{~g} / \mathrm{dm}^{3}$. Added to this, the acid exhibits a selective capacity for complex formation with lead in alkaline solution.

The processing technology for technogenic wastes includes three main stages: technogenic accumulation leaching, metal separation, and deposition in solid form from solution.

Technogenic accumulation leaching is performed in two stages. The first is waste treatment with complexing agent alkaline solution at $\mathrm{pH}=10-11$, and then the solution obtained is acidified with sulfuric acid to $\mathrm{pH} 1-0.7$ as a result of which lead phosphonate is deposited. The deposit is filtered, dissolved by alkalizing to $\mathrm{pH}=10$ with preparation of finished lead electrolyte. Using the acid solution from lead deposition, the second leaching stage is carried out for solid residue from the first (alkaline) leaching. As a result of this, the rest of the valuable metals and iron are extracted into solution. The solid residue from the second (acid) leaching contains barren rock minerals and is enriched in precious metals. It may be used as a fluxing addition in melting sulfide copper concentrates into matte.

The acid solution of the second (acid) leaching is treated with alkaline reagent with a stepwise increase in $\mathrm{pH}$. With an increase in solution alkalinity there is selective deposition from it at first of copper compounds, then zinc and iron. The deposit containing metals is dissolved by acidification with preparation of appropriate electrolytes.

The electrolytes obtained as a result of dissolving deposits are used for electrolytic extraction of metals in the form of finished product. The exhausted electrolytes are combined and after adjustment of $\mathrm{pH}$ and complexing agent concentration are sent to the head of the process in the first stage, i.e., alkaline leaching.

Thus, the production cycles for processing technogenic lead-containing intermediates using complexing reagents are closed and more ecologically clean compared with pyrometallurgical methods.

The article was prepared within the scope of the Federal Targeted Program on Scientific and Teaching Staff for an Innovative Russia for 2009-2013 (State Contract No. 16.740.11.0669).

\section{REFERENCES}

1. S. S. Naboichenko, S. V. Karelov, S. V. Mamyachenkov, and S. A. Yakornov, Izv. Vyssh. Uchebn. Zaved. Gorn. Zh., No. 11-12, 252-257 (1997).

2. S. V. Karelov, S. V. Mamyachenkov, S. S. Naboichenko, and S. A. Yakornov, Tsvet. Met., No. 2, 17-20 (1994).

3. S. A. Vzorodov, Dissertation for Cand. Tech. Sci., Sverdlovsk (1985).

4. $\quad$ S. V. Karelov, V. A. Sergeev, A. M. Panyshin, et al., Tsvet. Met., No. 6, 29-31 (2009).

5. S. V. Karelov, O. S. Anisomova, S. V. Mamyachenkov, and S. V. Sergeev, Tsvet. Met., No. 2, $20-23$ (2008).

6. S. V. Karelov, O. S. Anisomova, S. V. Mamyachenkov, and S. V. Sergeev, Izv. Vyssh. Uchebn. Zaved. Tsvet. Met., No. 2, 20-24 (2008). 